\title{
Mineralogical and Geochemical Characteristics of Caprock Formations Used for Storage and Sequestration of Carbon Dioxide
}

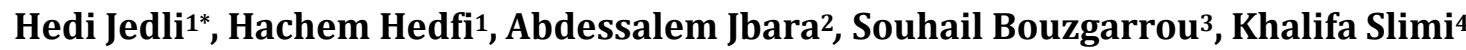 \\ ${ }^{1}$ National Engineering School of Monastir University, Monastir, Tunisia \\ ${ }^{2}$ Higher Institute for Sciences and Energy Technology, Gafsa University, Gafsa, Tunisia \\ ${ }^{3}$ National Engineering School of Tunis, Tunis El Manar University, Tunis, Tunisia \\ ${ }^{4}$ Higher Institute for Transport and Logistics, Sousse University, Sousse, Tunisia \\ Email: ${ }^{*}$ jedli.hedi@yahoo.com
}

Received 5 July 2015; accepted 23 August 2015; published 26 August 2015

Copyright (C) 2015 by authors and Scientific Research Publishing Inc.

This work is licensed under the Creative Commons Attribution International License (CC BY).

http://creativecommons.org/licenses/by/4.0/

c) (i) Open Access

\begin{abstract}
The main objective of the present study is to characterize cap rock formation used for geological storage of carbon dioxide $\left(\mathrm{CO}_{2}\right)$. The petrophysical properties of several rocks were studied before $\mathrm{CO}_{2}$ injection. This step is necessary for an understanding of $\mathrm{CO}_{2}$-brine-rock interactions. The mineralogical composition of several clay samples collected from real storage sites located in the south of Tunisia was determined by X-ray diffraction (XRD) and Scanning Electron Microscopy (SEM) coupled to a probe EDS, infrared spectroscopy, thermal analysis and fluorescence spectra. The obtained experimental results reveal that illite, calcite and quartz are the dominant clay minerals. Dolomite and albite are also present. Besides, SEM analysis shows laminated structure for these samples which suggests low crystallinity. This sample contains a higher content of $\mathrm{Fe}, \mathrm{Cl}, \mathrm{Ca}$ and $\mathrm{O}$. The clay cover may also be useful in storage process by immobilizing the migration of $\mathrm{CO}_{2}$ outer of the geological site and activating the process of mineral sequestration.
\end{abstract}

\section{Keywords}

Carbon Dioxide Storage, Cap Rock, Clay, X-Ray Diffraction, Scanning Electron Microscopy, Thermal Analysis, Infrared Spectroscopy, Fluorescence Spectra

\footnotetext{
"Corresponding author.
}

How to cite this paper: Jedli, H., Hedfi, H., Jbara, A., Bouzgarrou, S. and Slimi, K. (2015) Mineralogical and Geochemical Characteristics of Caprock Formations Used for Storage and Sequestration of Carbon Dioxide. Journal of Minerals and Materials Characterization and Engineering, 3, 409-419. http://dx.doi.org/10.4236/jmmce.2015.35043 


\section{Introduction}

The development of carbon capture and storage (CCS) technique aims to reduce the atmospheric concentration of greenhouse gases emitted by industrial activities [1]. The carbon dioxide $\left(\mathrm{CO}_{2}\right)$ captured from large stationary sources can be safely injected and stored in appropriate geological formations, such as deep saline formations and depleted oil and gas reservoirs [2]. These geological formations are considered as the most stable in the $\mathrm{CO}_{2}$ storage process on long term scale [3]. Four trapping and storing mechanisms are widely discussed in the CCS literature: residual, structural, mineral trapping and hydrodynamic [4]. After $\mathrm{CO}_{2}$ injection, the cover rocks constitute the first barrier preventing the migration of $\mathrm{CO}_{2}$ outer the geological reservoir. Generally, the most effective caprocks are siliciclastics (clay), evaporites (gypsum, anhydrites, halites) and organic-rich rocks [5]. The long-term confinement of $\mathrm{CO}_{2}$ injected in the deep reservoir will be crucially dependent on cap rock and $\mathrm{CO}_{2}$ interaction. The reaction between $\mathrm{CO}_{2}$ and two-caprock samples of carbonate and clay-types has been studied in a laboratory reactor under the conditions of geological storage [6]. It has been shown a change in mineralogical compositions for the two samples. Using gravimetric method, the sorption capacity and kinetics of $\mathrm{CO}_{2}$ have been measured among the clay minerals (montmorillonite, illite, and sepiolite) [7]. A thermodynamic study of $\mathrm{CO}_{2}$ adsorption has been performed on different adsorbents (Clay, Jurassic evaporates and Triassic sandstone) [8]. This study evaluated the best material able to absorb the maximum of $\mathrm{CO}_{2}$ and therefore to optimize the choice of the storage site. The $\mathrm{CO}_{2}$-brine-rock interaction can also generate some new mineral precipitation so as to change the properties of the reservoir. The properties change can influence the physical and chemical retention mechanisms of $\mathrm{CO}_{2}$ (drainage and imbibitions) [9]. Pressure and temperature effects on the reactivity of the host rock minerals with supercritical $\mathrm{CO}_{2}$ have been studied by Regnault et al. [10]. The authors have discussed $\mathrm{CO}_{2}$ storage capacity, mechanical reservoir behavior and chemical alteration. Other experimental studies and theoretical methods have been interested in the forsterite dissolution and magnesite precipitation at geological storage conditions [11]. Their experiments offer insights into the effects of relevant temperature and $\mathrm{CO}_{2}$ pressure levels on mineral dissolution and carbonate precipitation. The chemical modification of the solid phase has been observed by scanning electron microscopy (SEM), infrared spectroscopy (IR), and X-ray diffraction techniques.

The clay cover rock was used to determine the change in electrical and capillary forces between clay, $\mathrm{CO}_{2}$ and water [12]. This change leads to chemo-hydro-mechanical phenomena that could facilitate $\mathrm{CO}_{2}$ break and advection through porosity cap rocks. Computational models [13] offer a means of comparing and selecting storage reservoirs (storage capacity, escape potential, risk analysis escape routes and storage). These models require an understanding of minerals clay effects on scales variety. Therefore, it is crucial to understand the cover rocks nature in order to assess the reactivity of these minerals with respect to $\mathrm{CO}_{2}$.

The main objective of the present experimental study is to examine the characteristics of some geological cap rocks from real site located in southern region of Tunisia. It aims to identify common features that may impact long-term $\mathrm{CO}_{2}$ storage. Four different simples of clay-type will be chosen for the experiments. Different techniques will be used to characterize the physical and chemical properties at different observation scales.

\section{Materials and Methods}

The present study deals with chemico-mineralogical characterization and technological properties of clay minerals, raw material collected from real site located in the city of Gabes in southern Tunisia. The site from which the samples are taken is drawn in Figure 1 [14].

$\mathrm{X}$-ray diffraction and infrared spectra allow us to describe the mineralogical compositions of the simples. The samples structure will be investigated using scanning electron microscope. While measurement of the mass change will be delineated by thermal analysis. However, the fluorescence measurement of the samples will be achieved by photoluminescence.

X-ray diffraction analysis was carried out by a "Philips MPD1880-PW1710" diffractometer using $\lambda_{\text {CuK } \alpha}$ radiation, in the $2^{\circ}-80^{\circ}$ interval with a step size of $0.02^{\circ}$ and counting time of $20 \mathrm{~s} / \mathrm{step}$. The quantification phase was performed on one sample by the Rietveld method (R-QPA), using a PANalytical X'Pert High-Score Plus program. The chemical analyses and composition of the rock samples and clay minerals were examined using a JEOL JSM 5600LV scanning electron microscope (SEM) coupled with an energy dispersive spectrometer (EDS) (Bruker AXS Microanalysis). Infrared spectra were obtained using a Vertex 70-RAM II Bruker spectrometer (Bruker Analytical, Madison, WI). Differential and thermo gravimetric analyses were obtained using 


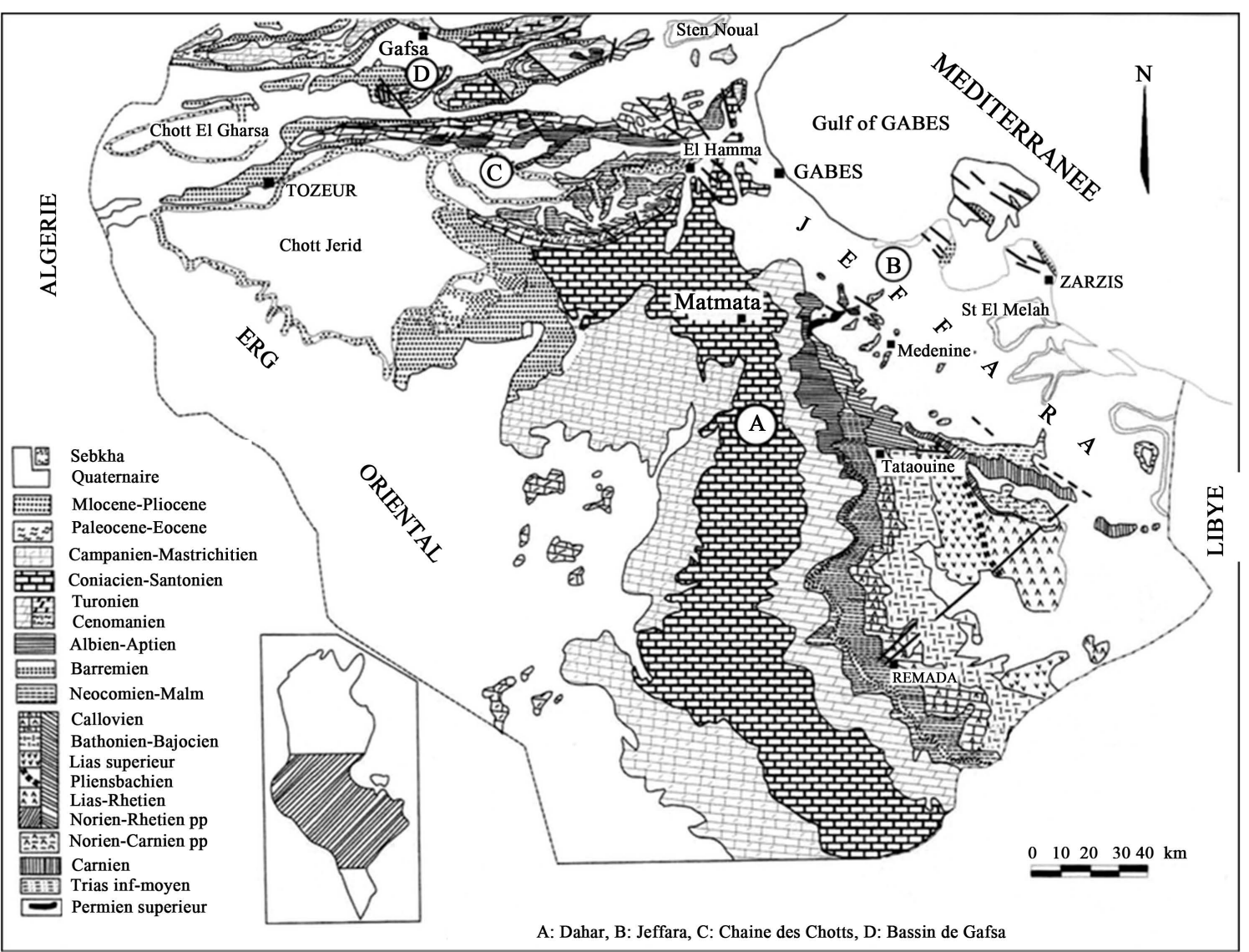

Figure 1. Location of El Hamma region in the city of Gabes located in southern Tunisia from which samples of claytype are collected.

an (ATG-DSC) STA 449C Netzsch instrument operating in helium atmosphere and heated at a rate of $20^{\circ} \mathrm{C}$ from room temperature to $1500^{\circ} \mathrm{C}$. Photoluminescence (PL) measurements were collected on a Jobin-Yvon Fluorolog 3 spectrometer using a Xenon lamp (500 W) at room temperature.

\section{Results and Discussion}

\subsection{X-Ray Diffraction (XRD)}

The mineralogical profile of the clay sample can be examined using X-ray diffraction in order to identify the crystalline components present in the clays. The XRD patterns of the clay samples had similar mineral compositions, consisting mainly of illite, calcite and quartz.

Figure 2 shows the X-ray diffraction pattern of the clay samples. The following mineralogical phases were identified: calcite (3.85 $\AA, 3.03 \AA$, $3.55 \AA$ ), illite (9.79 $\AA$ and $9.79 \AA$ ) and quartz (4.26 $\AA$ and $3.35 \AA$ ) as the principal minerals. Other secondary mineral phases are also found in this clay such as dolomite (2.88 $\AA$ ). The mineralogical compositions of raw materials obtained with XRD analysis summarized in Table 1, indicate that the mineral association is the same in all cases and corresponds to the mixture of Calcite, Illite, Quartz, Dolomite and Albite.

\subsection{Scanning Electron Microscope (SEM)}

The surface topographies of different studied compounds are analyzed by scanning electron microscope (SEM) and energy dispersive X-ray spectroscopy (EDS) (Figure 3). The SEM imaging shows that clay occurs as crystals of variable sizes of undefined outlines and edges. Then, the particle morphology is shown to be laminated. EDS analysis allows us to identify that the samples of clay-type are dominated by $\mathrm{Si}, \mathrm{Cl}, \mathrm{Na}$, and $\mathrm{O}$. 


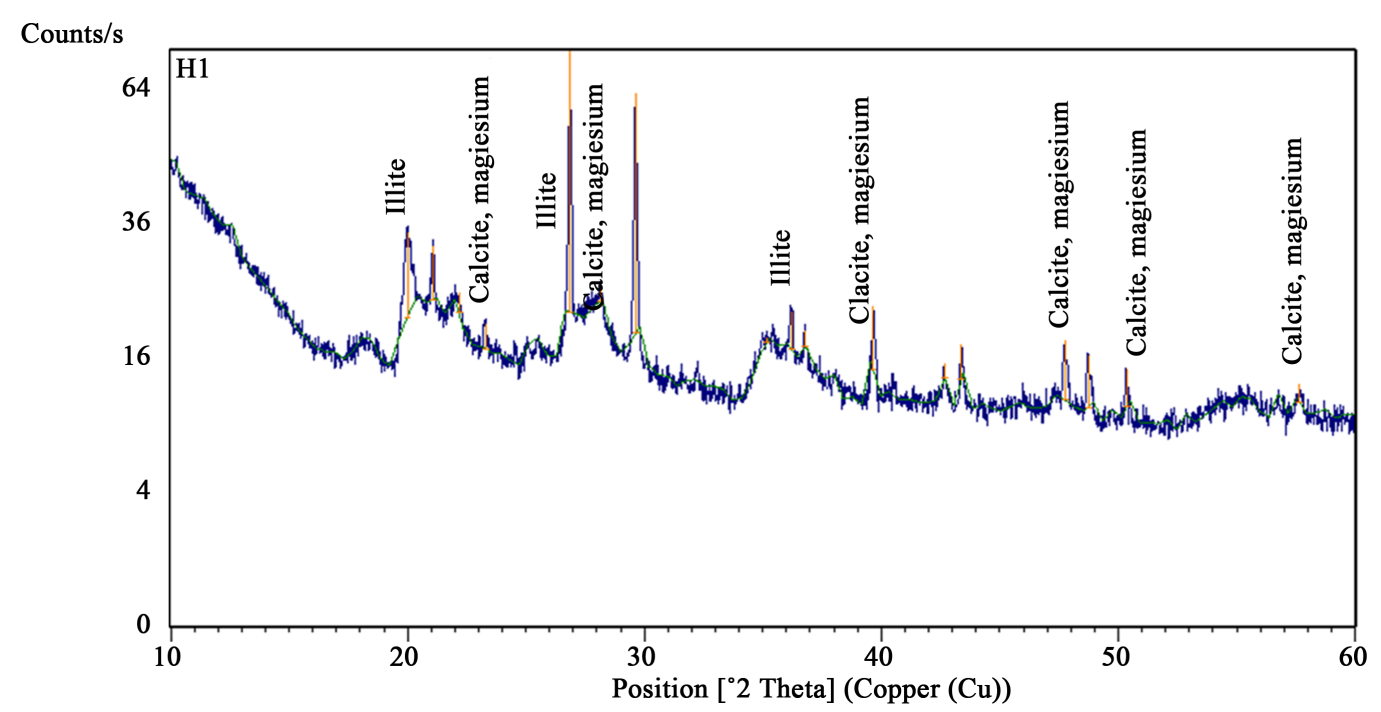

(a)

Counts/s

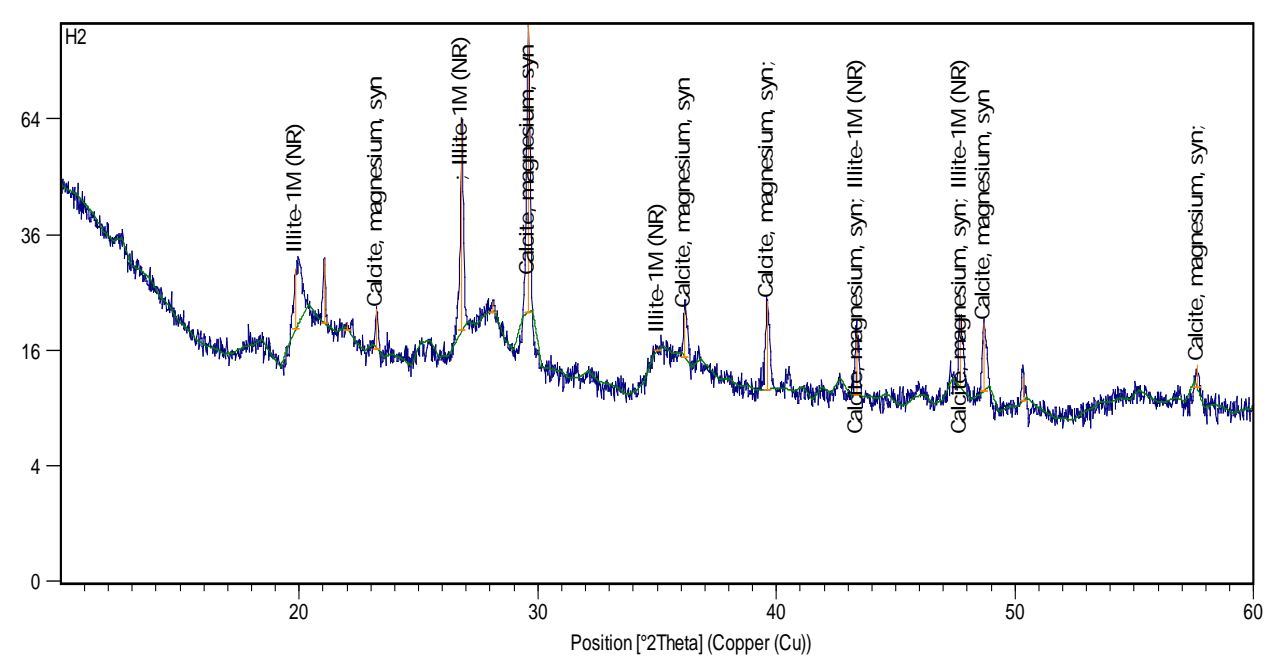

(b)

Counts/s

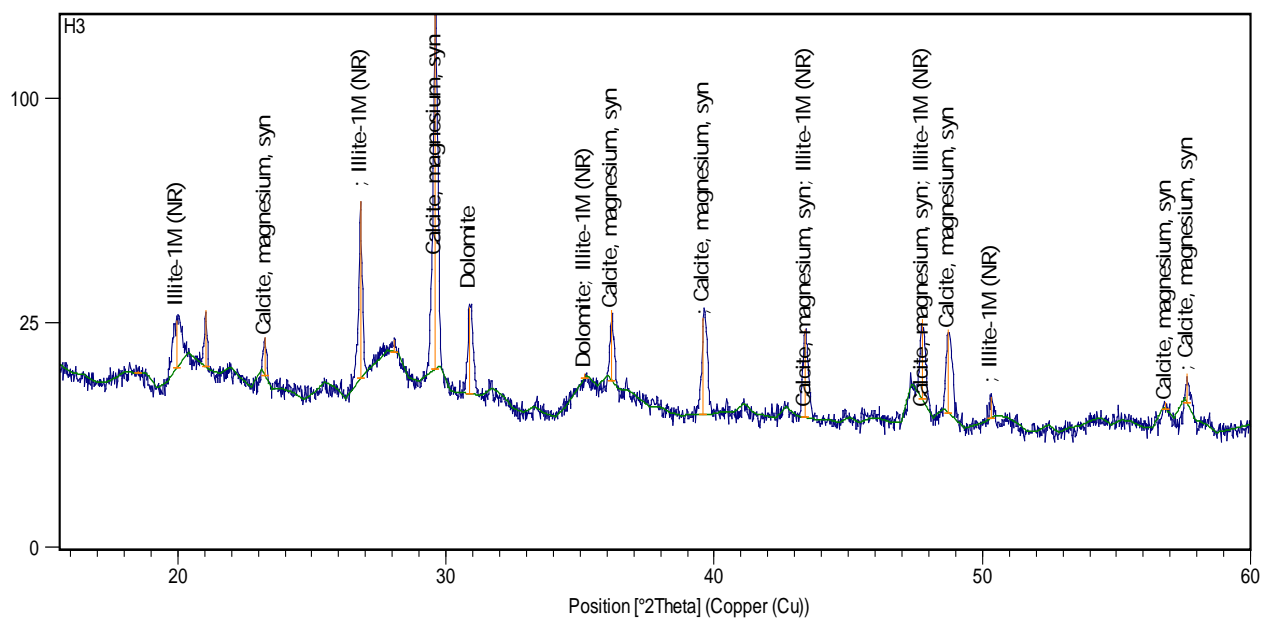

(c) 


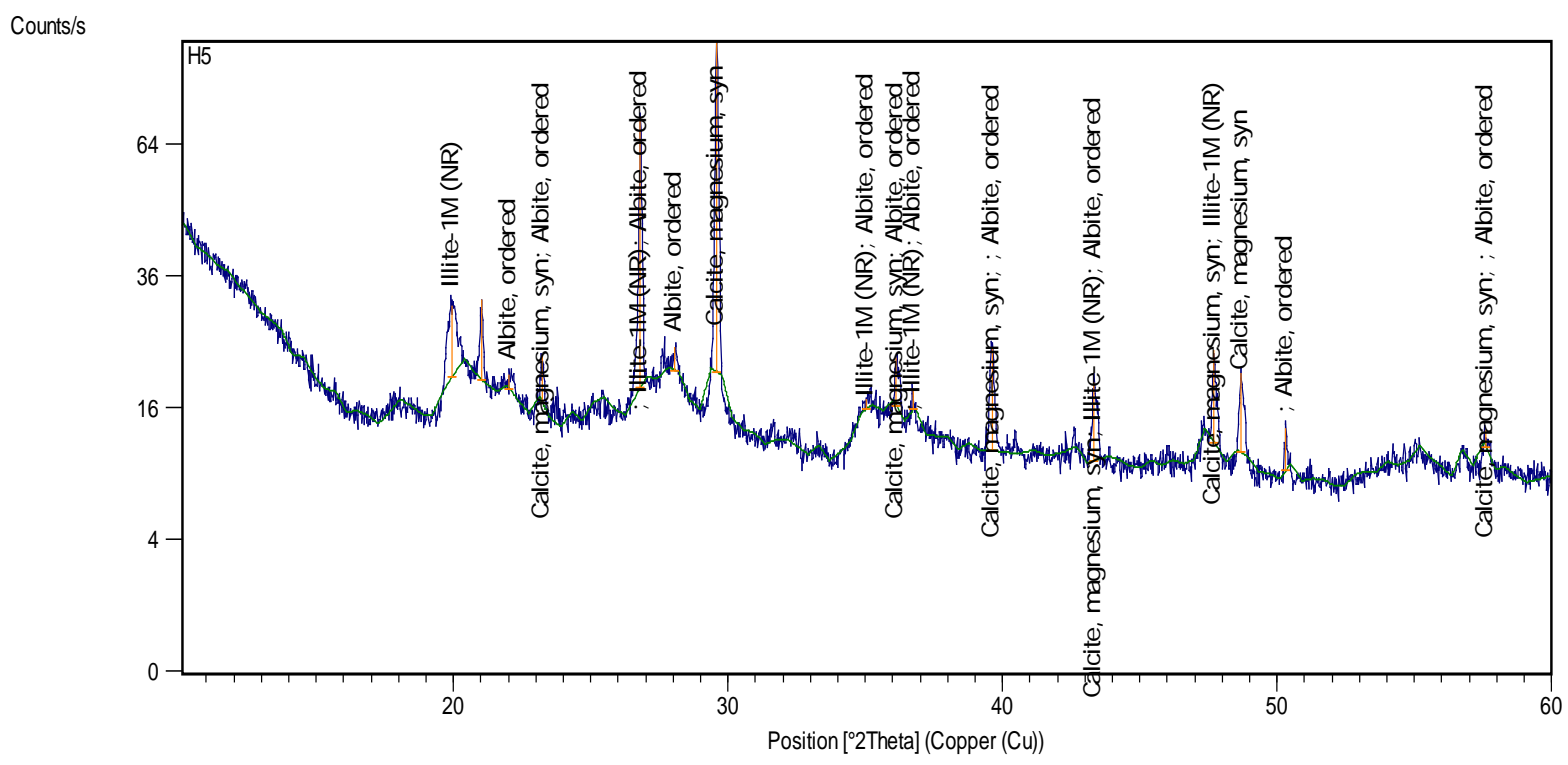

(d)

Figure 2. XRD spectra of different samples. (a) Sample 1; (b) Sample 2; (c) Sample 3; (d) Sample 4.
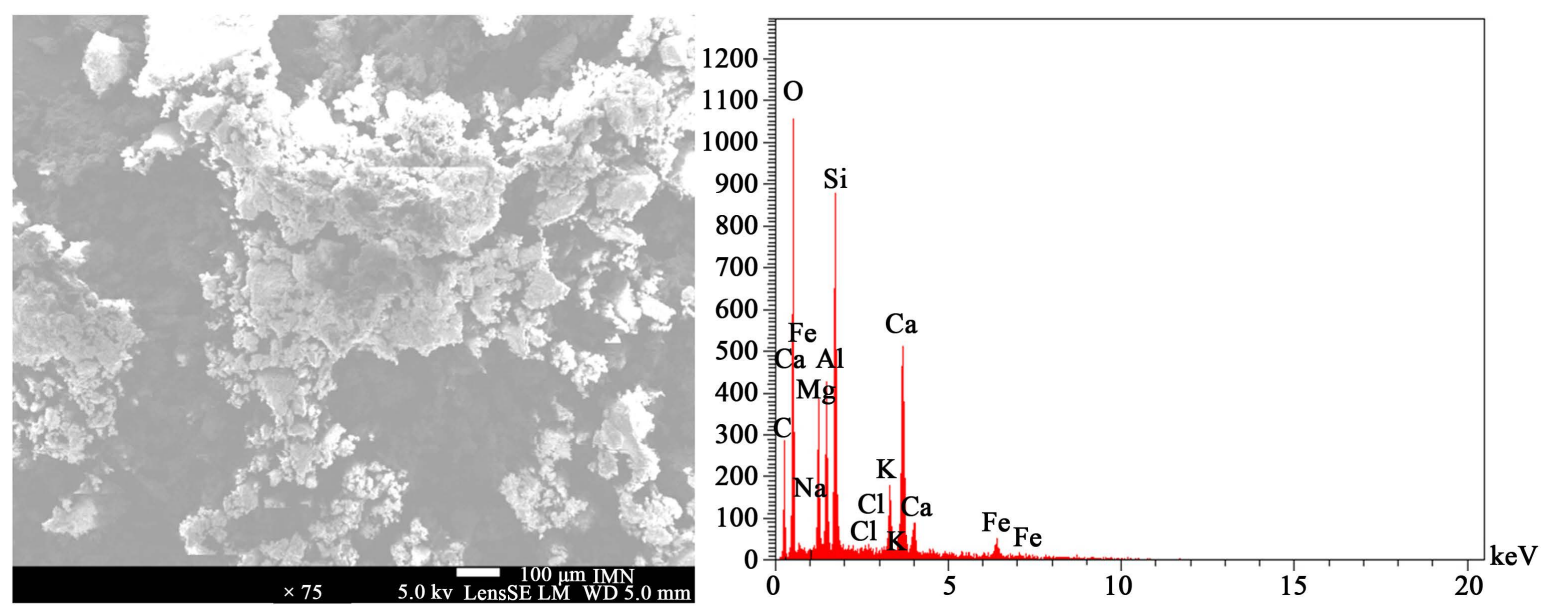

(a)
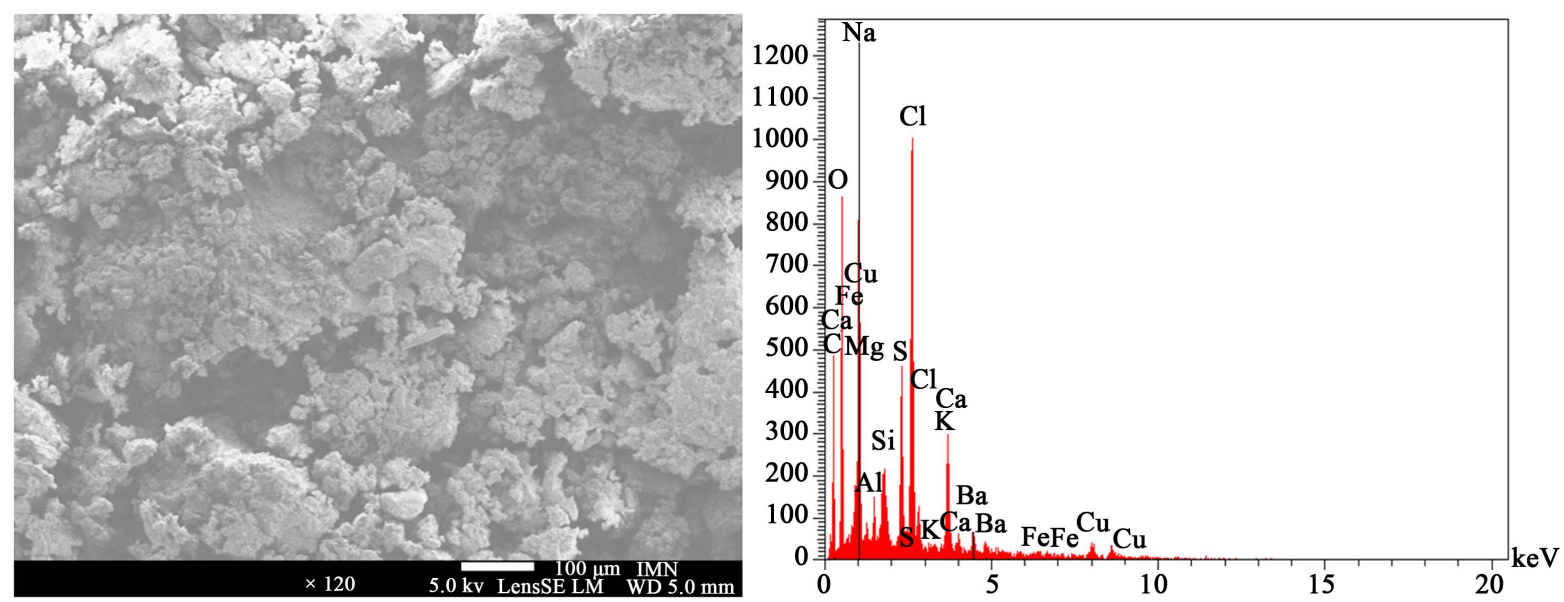

(b) 

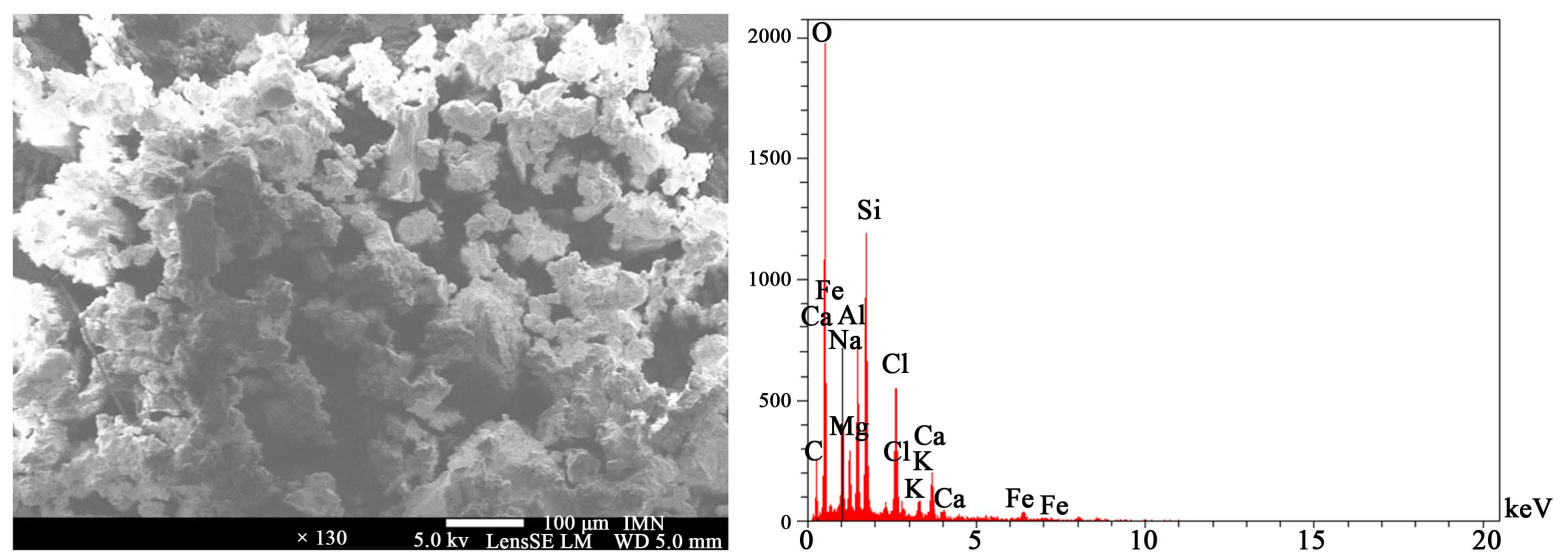

(c)
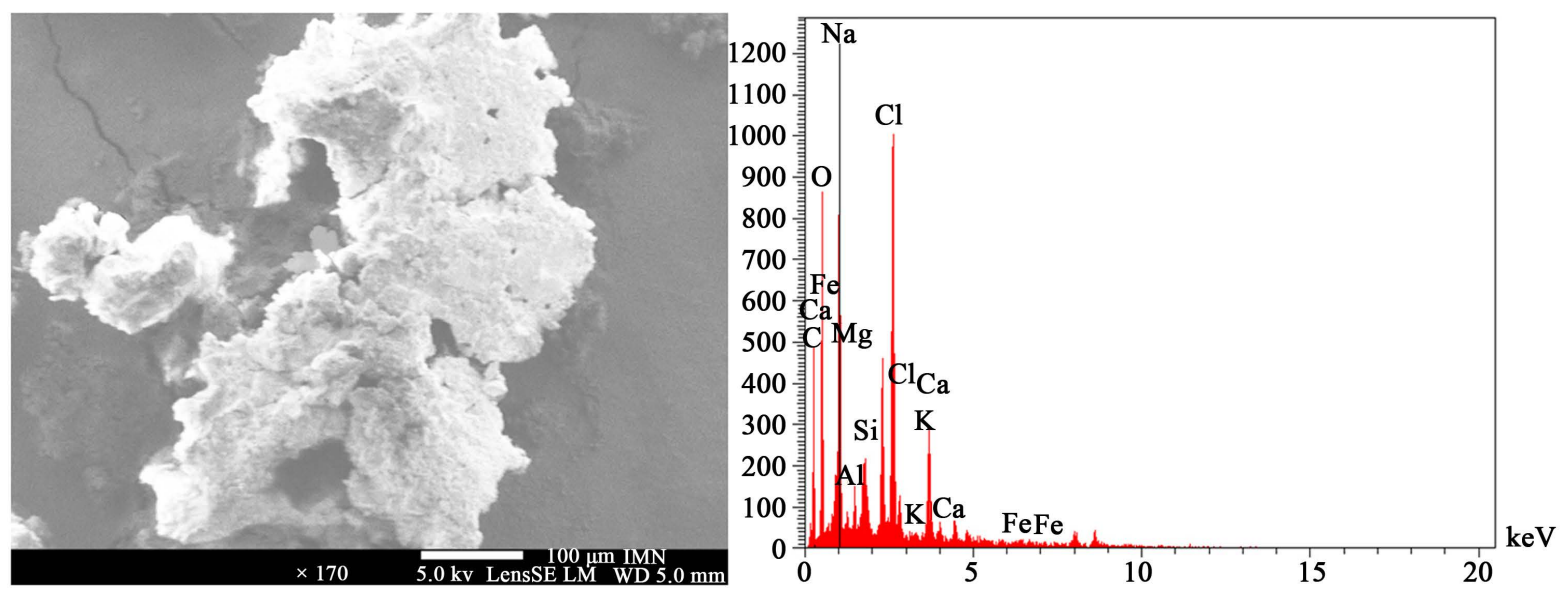

(d)

Figure 3. SEM image and with EDS analysis of different samples. (a) Sample 1; (b) Sample 2; (c) Sample 3; (d) Sample 4.

Table 1. XRD mineralogy analysis (wt\%) of different samples of clay-type.

\begin{tabular}{ccccccc}
\hline Sample & Quartz & Calcite & Illite & Dolomite & Albite & Sum \\
\hline S1 & 31 & 23 & 46 & - & - & 100 \\
S2 & 15 & 51 & 34 & - & - & 100 \\
S3 & 8 & 47 & 32 & 12 & - & 100 \\
S4 & 30 & 43 & 24 & - & 3 & 100 \\
\hline
\end{tabular}

\subsection{Infrared Spectroscopy}

Infrared technique has been frequently used for the identification of natural clay minerals, the minerals such as kaolinite, illite and quartz were identified by comparing the observed wave numbers with available literature [15] and [16]. The absorption profiles of the four chosen clay samples, S1-S4, are roughly similar, as depicted in Figure 4, showing the presence of $\mathrm{OH}$-stretching bands in the vicinity of $3400 \mathrm{~cm}^{-1}$. The Si-O stretching bands near $1000 \mathrm{~cm}^{-1}$ indicate the presence of illite [17]. The characteristic band at $1428 \mathrm{~cm}^{-1}$ suggesting the presence of carbonate (calcite or dolomite) [15]. The appearance of intensity at 794 and $779 \mathrm{~cm}^{-1}$ in all spectra is considered an indication of quartz [16]. The bands at $669 \mathrm{~cm}^{-1}$ and $647 \mathrm{~cm}^{-1}$ confirmed the presence of plagioclase (albite or anorthite). However, the band at $1625 \mathrm{~cm}^{-1}$ is attributed to hydrogen bonded water and corresponds to the position of the water bending mode of liquid water [18]. Indeed, the stretching vibration of $\mathrm{OH}$ bonds at $3630 \mathrm{~cm}^{-1}$ clearly indicate the presence of kaolinite [19]. 


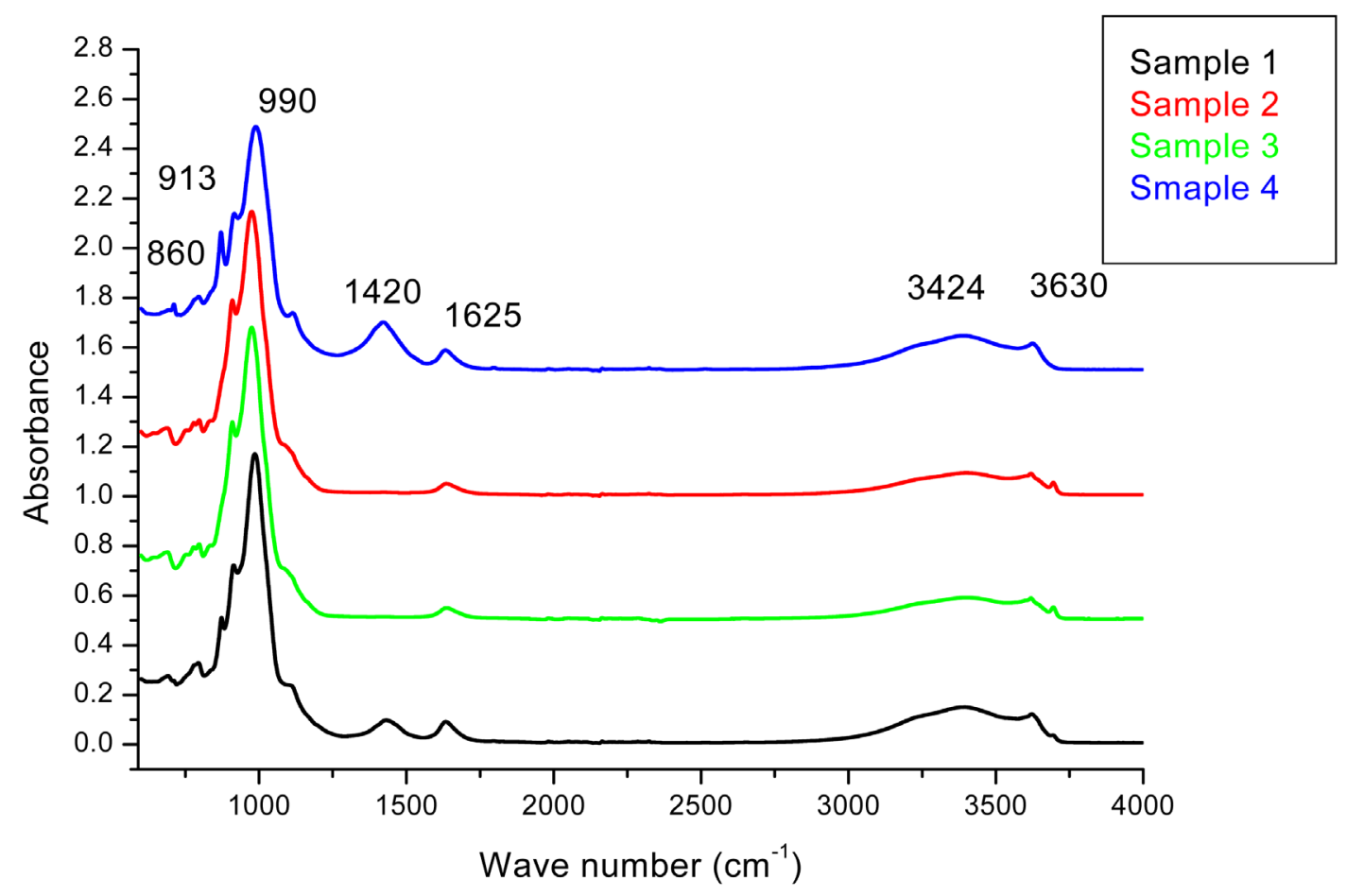

Figure 4. Infrared spectra of different samples.

\subsection{Thermal Analysis}

In accordance with related published papers [20] and [21], our results obtained with differential thermal analysis (DTA) and thermal gravimetric analysis (TGA) for simples of clay-types are illustrated in Figure 5. For all the selected samples, DTA curves reveal similarities in low-temperature range. Moreover, one can observe an endothermic peak system at low temperatures $\left(<200^{\circ} \mathrm{C}\right)$ corresponding to the loss of hydration water. A strong endothermic peak appears at the temperature range of $509^{\circ} \mathrm{C}-515^{\circ} \mathrm{C}$ which is related to the departure of constitution water resulting from the dehydroxylation of clay minerals [21]. Another endothermic peak is observed at about $730^{\circ} \mathrm{C}$ due to the decomposition of carbonates [22]. The mass loss associated to this peak is summarized in Table 2.

\subsection{Fluorescence Spectra}

Regarding preliminary experiments performed prior to $\mathrm{CO}_{2}$ storage, Figure 6 provides cartographies photoluminescence PL (excitation-emission) in false colors performed on the four chosen simples. For more clarity, cartography colors going from blue to red represent the increasing of the PL intensity depicting steady-state PL emission versus PL excitation (PLE). The emission patterns were varied among samples allowing their classification. The response of the four samples is situated in the spectral region from 330 to $480 \mathrm{~nm}$ for an excitation wavelength range 220 - $280 \mathrm{~nm}$. These cartographies show also that the intensity of emission is maximized at the spectral region varying from 440 to $470 \mathrm{~nm}$ (red color) for an excitation wavelength between 240 and 260 $\mathrm{nm}$. The prompt view of these maps shows qualitatively that the PL spectrum is broad in the case of S4 compared to the other samples (S1, S2 and S3).

\section{Concluding Remarks}

The present experimental research aimed to examine the chemical characteristics of cap rock formations considered for $\mathrm{CO}_{2}$ storage process. Different characterization techniques have been used to characterize the cover rock. Experimental results obtained with DRX demonstrated the presence of quartz, illite, Calcite, and Dolomite for the different selected samples of clay-type. The presence of these minerals was also confirmed by IR analysis. 


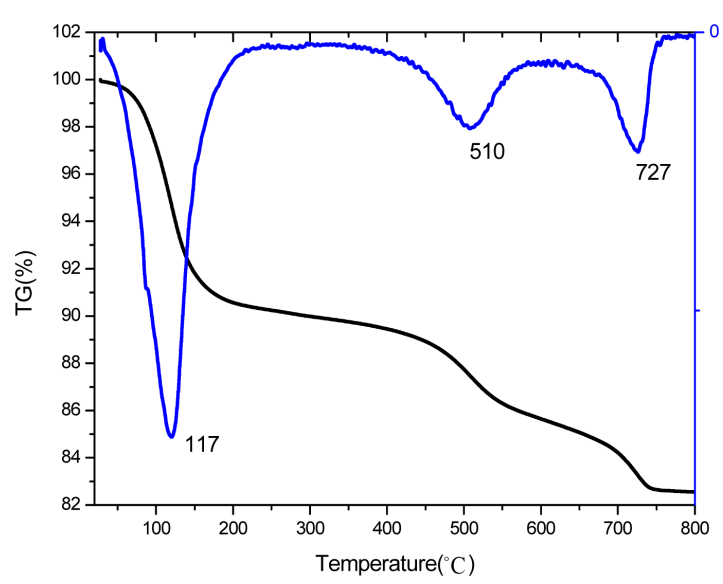

(a)

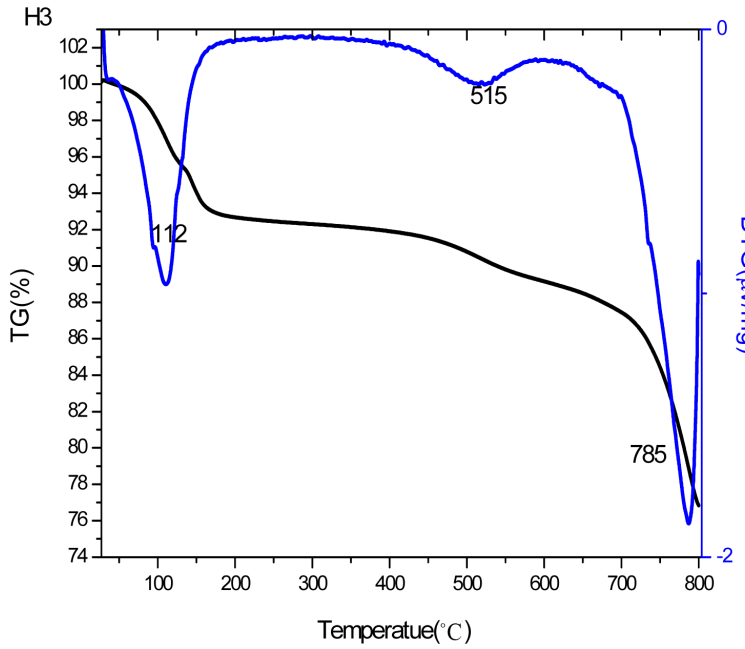

(c)

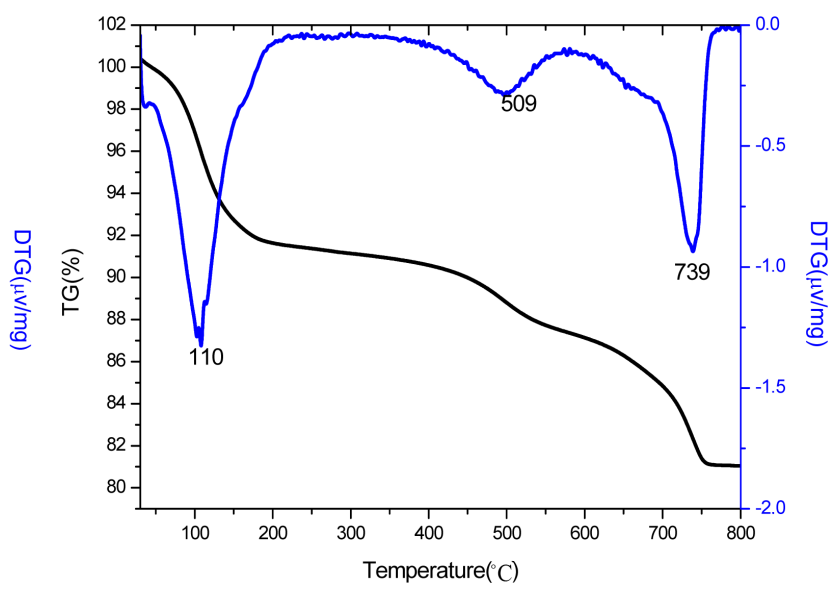

(b)

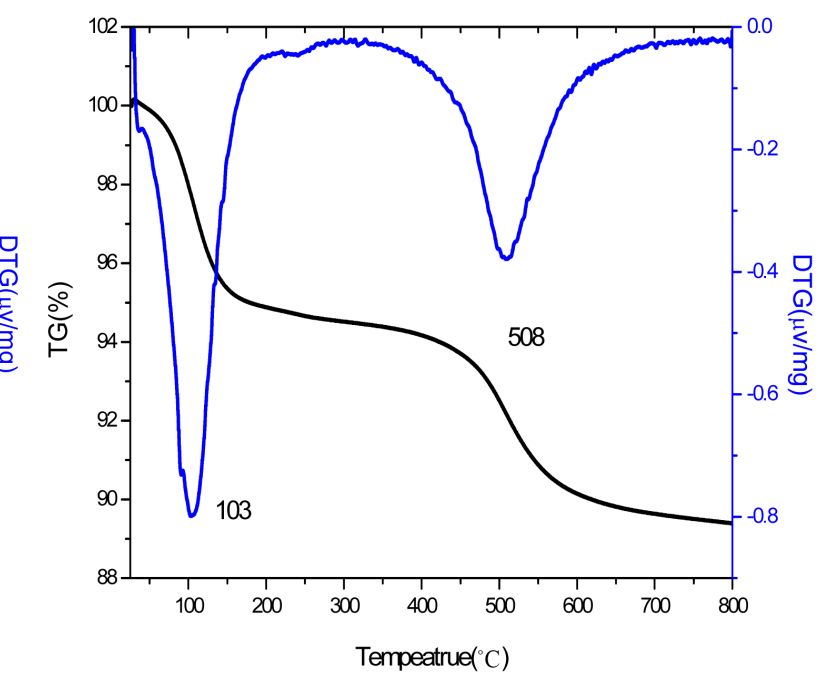

(d)

Figure 5. TG-DTA curves of different samples. (a) Sample 1; (b) Sample 2; (c) Sample 3; (d) Sample 4.

Table 2. The mass loss associated to the endothermic peak for different samples of clay-type at different temperature levels.

\begin{tabular}{ccc}
\hline Sample & Temperature $\left({ }^{\circ} \mathbf{C}\right)$ & Mass loss (\%) \\
\hline \multirow{3}{*}{ S1 } & 119 & 9.68 \\
& 510 & 7.77 \\
& 727 & 0.71 \\
& 108 & 8.66 \\
S2 & 500 & 4.08 \\
& 738 & 6.32 \\
& 110 & 7.69 \\
S3 & 522 & 3.06 \\
& 782 & 12.41 \\
& 103 & 5.51 \\
& 510 & 510 \\
\hline
\end{tabular}



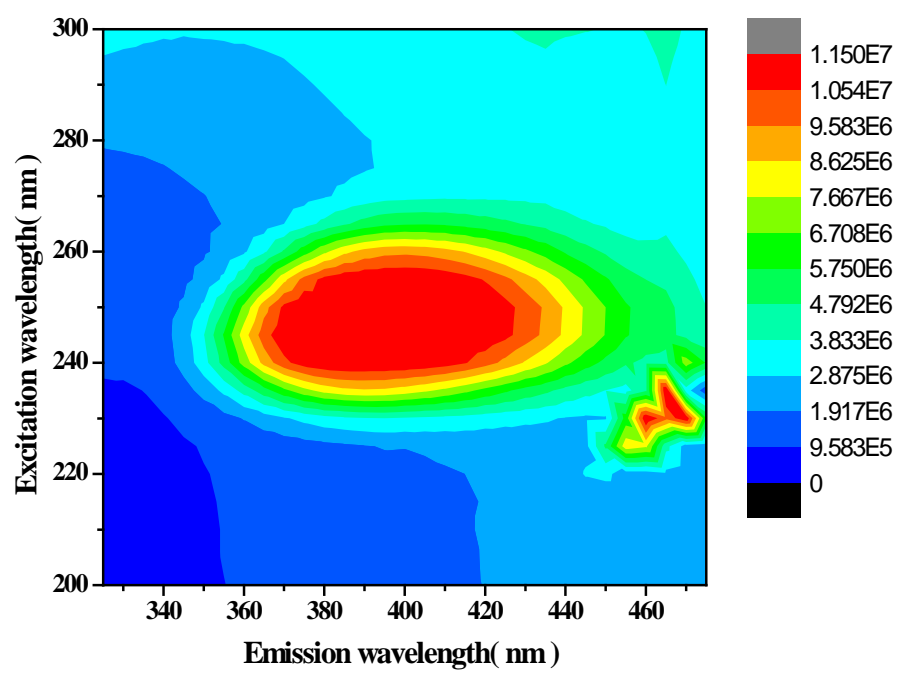

(a)
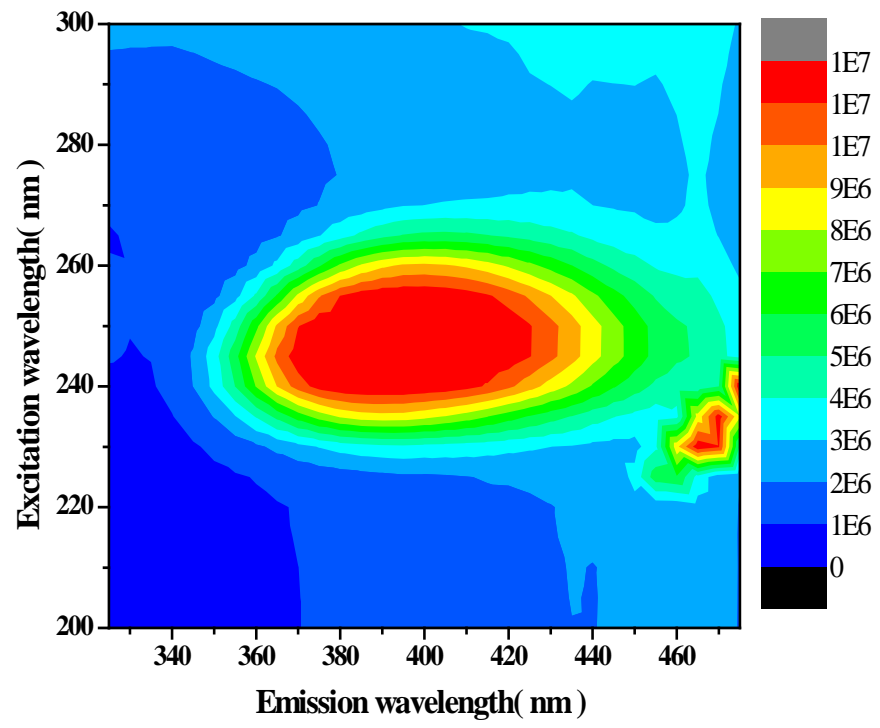

(b)

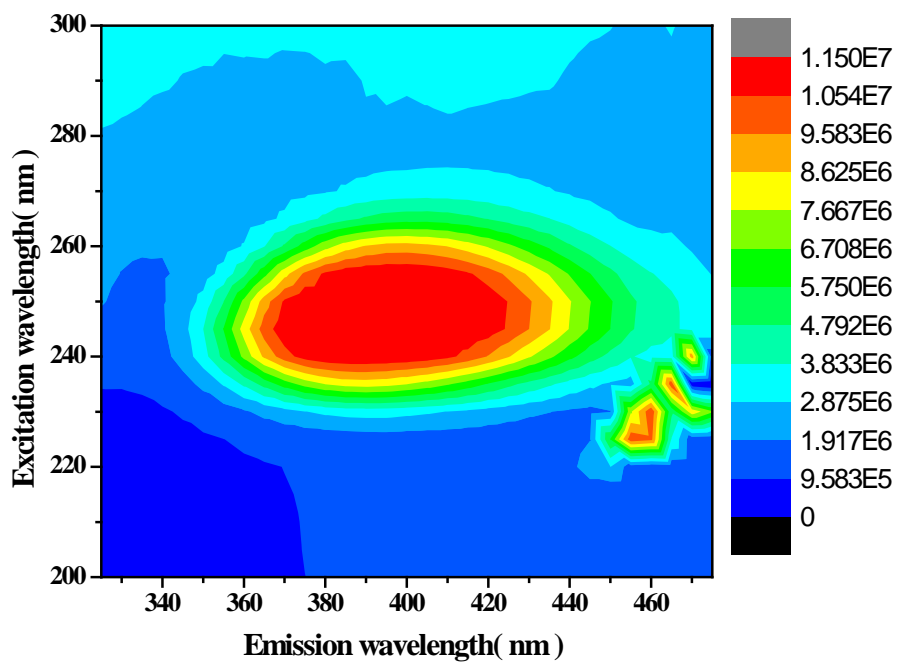

(c) 


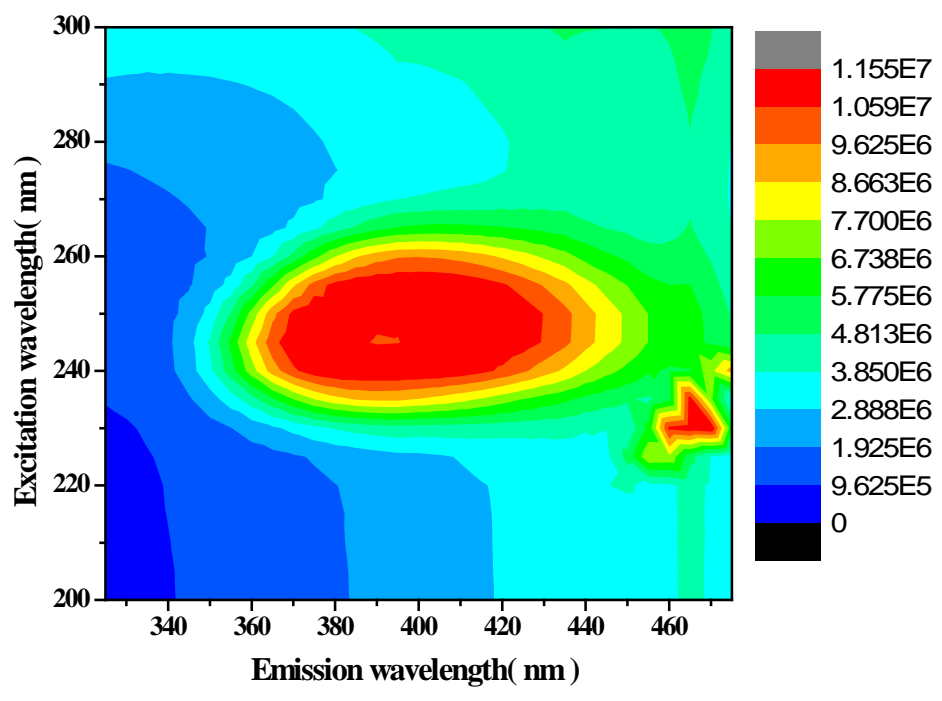

(d)

Figure 6. Cartographies PL spectra of different samples. (a) Sample 1; (b) Sample 2; (c) Sample 3; (d) Sample 4.

EDX analyses justified that these clays were rich in $\mathrm{Si}, \mathrm{Cl}$, Na and $\mathrm{O}$ accompanied by a significant number of iron oxides. The DTA curves of clay samples revealed that three endothermic peaks were mainly due to the loss of $\mathrm{H}_{2} \mathrm{O}$ from clay minerals and from the carbonates decomposition. Florescence results indicated that the spectrum was broad in the case of sample S4. Moreover, the obtained experimental results offered us a means of evaluating, comparing, and selecting storage reservoirs on criteria such as ease of injection, storage capacity, migration, and escape of $\mathrm{CO}_{2}$ from a potential reservoir.

\section{Acknowledgements}

The authors would like to express their gratitude to the members of the Physics Complex Systems Laboratory at the University Picardy Jule Verne in France for their kind help in the characterization process of selected samples with fluorescence spectra and thermal analysis.

One of the authors (Mr. Hedi Jedli) is grateful to the Tunisian Ministry of Higher Education and Scientific Research for the grant in the framework of "Bourse d'alternance".

\section{References}

[1] Bachu, S. (2000) Sequestration of $\mathrm{CO}_{2}$ in Geological Media in Response to Climate Change: Road Map for Site Selection Using the Transform of the Geological Space into the $\mathrm{CO}_{2}$ Phase Space. Energy Conversion and Management, 43, 87-102. http://dx.doi.org/10.1016/S0196-8904(01)00009-7

[2] Jean-Baptiste, P. and Ducroux, R. (2003) Potentiel des méthodes de séparation et stockage du $\mathrm{CO}_{2}$ dans la lutte contre l'effet de serre. Comptes Rendus Geoscience, 335, 611-625. http://dx.doi.org/10.1016/S1631-0713(03)00086-5

[3] Bachu, S. (2008) $\mathrm{CO}_{2}$ Storage in Geological Media: Role, Means, Status and Barriers to Deployment. Progress in Energy and Combustion Science, 34, 254-273. http://dx.doi.org/10.1016/j.pecs.2007.10.001

[4] Labus, K., Tarkowski, W. and Dowin, M. (2015) Modeling Gas-Rock-Water Interactions in Carbon Dioxide Storage. International Journal of Environmental Science and Technology, 12, 2493-2502. http://dx.doi.org/10.1007/s13762-014-0652-6

[5] Olabodea, A. and Radonjica, M. (2013) Experimental Investigations of Caprock Integrity in $\mathrm{CO}_{2}$ Sequestration. Energy Procedia, 37, 5014-5025. http://dx.doi.org/10.1016/j.egypro.2013.06.415

[6] Binyam, A., Aagaard, L. and Skurtveit, P. (2011) Caprock Interaction with $\mathrm{CO}_{2}$ : A Laboratory Study of Reactivity of Shale with. Applied Geochemistry, 26, 1975-1989. http://dx.doi.org/10.1016/j.apgeochem.2011.06.028

[7] Pil Rip, J., Jiwon, C., Tae Sup, T. and Chang-Ha, L. (2014) Sorption Equilibrium and Kinetics of $\mathrm{CO}_{2}$ on Clay Minerals from Subcritical to Supercritical Conditions: $\mathrm{CO}_{2}$ Sequestration at Nanoscale Interfaces. Chemical Engineering Journal, 255, 705-715. http://dx.doi.org/10.1016/j.cej.2014.06.090 
[8] Bouzgarrou, S., Jedi, H., Stiti, N., Hamdi, N. and Slimi, K. (2015) Experimental Adsorption and Modelisation of $\mathrm{CO}_{2}$ on Adsorbents Collected from Elborma Field in South Tunisia. Journal of Surface Engineered Materials and Advanced Technology, 5, 52-63. http://dx.doi.org/10.4236/jsemat.2015.51006

[9] Galán, E. and Aparicio, P. (2014) Experimental Study on the Role of Clays as Sealing Materials in the Geological Storage of Carbon Dioxide. Applied Clay Science, 87, 22-27. http://dx.doi.org/10.1016/j.clay.2013.11.013

[10] Regnault, O., Lagneau, V., Catalette, H. and Schneider, H. (2005) Étude expérimentale de la réactivité du $\mathrm{CO}_{2}$ supercritique vis-à-vis de phases minérales pures. Implications pour la séquestration géologique de $\mathrm{CO}_{2}$. Comptes Rendus Geoscience, 337, 1331-1339. http://dx.doi.org/10.1016/j.crte.2005.07.012

[11] Giammara, D. and Petersb, R. (2005) Forsterite Dissolution and Magnesite Precipitation at Conditions Relevant for Deep Saline Aquifer Storage and Sequestration of Carbon Dioxide. Chemical Geology, 217, 257-276. http://dx.doi.org/10.1016/j.chemgeo.2004.12.013

[12] Espinoza, D. and Santamarina, J. (2012) Clay Interaction with Liquid and Supercritical $\mathrm{CO}_{2}$ : The Relevance of Electrical and Capillary Forces. International Journal of Greenhouse Gas Control, 10, 351-362. http://dx.doi.org/10.1016/j.ijggc.2012.06.020

[13] Waldo, P. (2012) Clay Minerals, Carbon Storage, and Effects of Observational Scale on Computational Models. Applied Clay Science, 53, 409-413. http://dx.doi.org/10.1016/j.clay.2010.09.012

[14] Mhamdi, A., Dhahri, F., Gouasmia, M., Inoubli, N., Soussi, M. and Dhia, H. (2013) Groundwater Investigation in the Southern Part of Gabes Using Resistivity Sounding, Southern Tunisia. Arabian Journal of Geosciences, 2, 601-614. http://dx.doi.org/10.1007/s12517-011-0375-7

[15] Paul, D. and Daniel, N. (2013) FT-IR Spectroscopy Applied for Surface Clays Characterization. Journal of Surface Engineered Materials and Advanced Technology, 3, 275-282. http://dx.doi.org/10.4236/jsemat.2013.34037

[16] Selmani, S., Essaidi, N., Gouny, F., Bouaziz, S., Joussein, E., Driss, A., Sdiri, A. and Rossignol, S. (2015) PhysicalChemical Characterization of Tunisian Clays for the Synthesis of Geopolymers Materials. Journal of African Earth Sciences, 10, 113-120. http://dx.doi.org/10.1016/j.jafrearsci.2014.12.009

[17] Torab, M., Angaji1, A., Zinali1, N. and Qazvini, N.T. (2013) Study of Physical, Chemical and Morphological Alterations of Smectite Clay upon Activation and Functionalization via the Acid Treatment. World Journal of Nano Science and Engineering, 3, 161-168. http://dx.doi.org/10.4236/wjnse.2013.34019

[18] Hajjaji, M., Kacim, S., Alami, A. and Bouadili, A.E. (2001) Chemical and Mineralogical Characterization of a Clay Taken from the Moroccan Meseta and a Study of the Interaction between Its Fine Fraction and Methylene Blue. Applied Clay Science, 20, 1-12. http://dx.doi.org/10.1016/S0169-1317(00)00041-7

[19] Sghaier, D., Chaabani, F., Proust, D. and Vieillard, P. (2014) Mineralogical and Geochemical Signatures of Clays Associated with Rhyodacites in the Nefza Area (Northern Tunisia). Journal of African Earth Sciences, 100, 267-277. http://dx.doi.org/10.1016/j.jafrearsci.2014.06.024

[20] Baccoura, H., Medhioubb, M., Jamoussic, F., Mhiria, T. and Daouda, A. (2008) Mineralogical Evaluation and Industrial Applications of the Triassic Clay Deposits, Southern Tunisia. Materials Characterization, 59, 1613-1622. http://dx.doi.org/10.1016/j.matchar.2008.02.008

[21] Eloussaiefa, M., Kallel, N., Yaacoubic, A. and Benzinaa, M. (2011) Mineralogical Identification, Spectroscopic Characterization, and Potential Environmental Use of Natural Clay Materials on Chromate Removal from. Chemical Engineering Journal, 168, 1024-1031. http://dx.doi.org/10.1016/j.cej.2011.01.077

[22] Felh, M., Tlil, A., Gaied, M. and Montacer, M. (2008) Mineralogical Study of Kaolinitic Clays from Sidi El Bader in the Far North of Tunisia. Applied Clay Science, 39, 208-217. http://dx.doi.org/10.1016/j.clay.2007.06.004 